\title{
Obstetric outcome in donor oocyte pregnancies: a matched-pair analysis
}

\author{
Dominic Stoop*, Miriam Baumgarten, Patrick Haentjens, Nikolaos P Polyzos, Michel De Vos, Greta Verheyen, \\ Michel Camus and Paul Devroey
}

\begin{abstract}
Background: To investigate the obstetrical and perinatal impact of oocyte donation, a cohort of women who conceived after OD was compared with a matched control group of women who became pregnant through in vitro fertilisation with autologous oocytes (AO).

Methods: A matched-pair analysis has been performed at the Centre for Reproductive Medicine of the UZ Brussel, Dutch speaking Free University of Brussel. A total of 410 pregnancies resulted in birth beyond 20 weeks of gestation occurring over a period of 10 years, including 205 oocyte donation pregnancies and 205 ICSI pregnancies with autologous oocytes (AO). Patients in the OD group were matched on a one-to-one basis with the AO group in terms of age, ethnicity, parity and plurality. Matched groups were compared using paired t-tests for continuous variables and McNemar test for categorical variables. A conditional logistic regression analyses was performed adjusting for paternal age, age of the oocyte donor, number of embryos transferred, and singleton/twin pregnancy.

Results: Oocyte donation was associated with an increased risk of pregnancy induced hypertension $(\mathrm{PIH})(\mathrm{matched}$ OR: 1.502 Cl: 1.024-2.204), and first trimester bleeding (matched OR: $1.493 \mathrm{Cl}: 1.036-2.15)$. No differences were observed between the two matched groups with regard to gestational age, mean birth weight and length, head circumference and Apgar scores.

Conclusions: Oocyte donation is associated with an increased risk for PIH and first trimester bleeding independent of the recipients' age, parity and plurality, and independent of the age of the donor or the partner. However, oocyte donation has no impact on the overall perinatal outcome.
\end{abstract}

Keywords: Oocyte donation, Pregnancy outcome, Pregnancy-induced hypertension, First trimester bleeding

\section{Background}

Oocyte donation (OD) has been introduced in 1984 to allow women with ovarian insufficiency to become pregnant [1]. The success of the technique led to a broadening of scope of the treatment to include indications of repeated IVF failure, advanced maternal age or inheritable disease [2]. Today, OD has become well established with thousands of children born worldwide annually. As with any other reproductive techniques, assessment of possible associated obstetric and perinatal risk remains of paramount importance.

Several authors have reported on the obstetrical and perinatal outcome after oocyte donation. Although these

\footnotetext{
* Correspondence: dominic.stoop@uzbrussel.be

Centre for Reproductive Medicine, Universitair Ziekenhuis Brussel, Vrije Universiteit Brussel, Laarbeeklaan 101, B-1090 Brussels, Belgium
}

case reports and series have shown varying results, the most consistently reported complications are a high incidence of pregnancy induced hypertension (PIH) and first trimester bleeding [3-7]. Most authors concluded that pregnancies after oocyte donation need to be considered as high risk pregnancies, however overall perinatal outcomes are considered favourable. [5-7].

Pregnancies after oocyte donation represent a unique group of pregnancies because they are achieved with an immunologically foreign embryo. This may underlie the observed increased obstetrical and perinatal risk associated with these pregnancies. However, obstetrical risk factors such as advanced maternal age, primiparity and multiple pregnancies tend to be more common in this population. Moreover, there is a higher incidence of potential obstetrical risk factors that necessitate oocyte 
donation treatment, such as previous pelvic radiation, immunologic disorders or severe endometriosis [8-10].

It remains unclear to which extent the increased obstetrical and perinatal risks can be attributed to immunological mechanisms or to the aforementioned confounding risk factors.

We therefore performed a retrospective analysis to investigate the impact of oocyte donation on the obstetric and perinatal outcome by comparing with a strictly matched control group. On a one-to-one basis, the oocyte recipient cohort was matched for age, ethnicity, parity and plurality, with a cohort of women who underwent invitro fertilisation treatment. Using this methodology we were able to minimise confounding bias and to investigate the effect of both oocyte donation and the underlying medical condition.

\section{Methods}

\section{Study design}

At the Dutch-speaking Brussels Free University, data collection with regard to the obstetrical and perinatal outcomes after oocyte donation and after ART have long been integrated into the clinical programme of the fertility centre [11]. All pregnancies that occurred between January 1999 and December 2008, that had been obtained after oocyte donation and resulted in offspring after more than 20 weeks of gestation, were included in this study. Matched controls were selected from the patient population that underwent in-vitro fertilisation with autologous oocytes during the same period. All pregnancies in oocyte recipients and in controls were conceived after intra cytoplasmic sperm injection (ICSI). Oocyte recipients underwent embryo transfer in natural cycles or in artificial cycles supplemented with a daily dose of $1600 \mathrm{mg}$ micronised progesterone and $10 \mathrm{mg}$ oestradiol valerate until $12^{\text {th }}$ weeks gestation. The individually matched controls were selected from a total of 3707 ICSI pregnancies reaching 20 weeks of gestation. Pregnancies after preimplantation genetic diagnosis (PGD) or after testicular sperm extraction (TESE) or use of donor sperm were not included in this study. The study was approved by the committe for ethics in medical research of the Free University of Brussels (12-5-2010; 2010/106; B.U. N.14320108637).

\section{Data collection}

For all pregnancies, written data regarding obstetrical and neonatal outcome were collected. As a routine procedure, a questionnaire is send to all patients with an ongoing pregnancy at seven weeks of gestation and to their obstetrician around the estimated delivery date. On average, $95 \%$ of the questionnaires are returned, while another $5 \%$ of the patients or their gynaecologists need to be contacted by phone in order to retrieve the outcome data. Obstetrical complications, perinatal data, including gestational age, mode of delivery, birth weight, Apgar scores, presence or absence of malformations and neonatal problems were registered. If any problem was mentioned, detailed information was requested from the paediatrician in charge.

\section{Matching procedure}

Matching was performed for maternal age (+/- 12 months), parity (nulliparity or multiparity), plurality (singleton or twin) and maternal ethnicity. Matching for the gender of the child was only performed in singleton pregnancies. Where multiple matching options existed, case-control pairs with concordant delivery dates were selected. None of the oocytes or embryos underwent cryopreservation prior to embryo transfer.

\section{Definitions}

Pregnancy-induced hypertension (PIH) was defined as blood pressure (BP) levels $>140 / 90 \mathrm{~mm} \mathrm{Hg}$ on two or more occasions at least $6 \mathrm{~h}$ apart, without proteinuria, after 20 weeks. Pre-eclampsia: repeated BP levels $\geq 140$ / $90 \mathrm{~mm} \mathrm{Hg}$ with proteinuria $\geq 0.3 \mathrm{~g} /$ day after 20 weeks of gestation. Gestational age: calculated from the day of oocyte aspiration, which was defined as day 14 of the cycle. Stillbirth: intrauterine or intrapartum death of a child born with a gestational age $\geq 20$ weeks or with a birth weight of $\geq 500$ g. Preterm birth: delivery before 37 completed weeks of gestation. Preterm premature rupture of the membranes (pPROM) was defined as rupture of the membranes before 37 weeks of gestation in the absence of uterine contractions. Perinatal mortality: number of intrauterine or intrapartum deaths and neonatal deaths $<7$ days after birth per 1000 children born with a gestational age of $\geq 20$ weeks. Low birth weight: < $2500 \mathrm{~g}$ at birth. Very low birth weight: < $1500 \mathrm{~g}$ at birth.

\section{Statistical analysis}

Categorical variables are presented as numerator and denominator values (\%), and continuous variables as mean (SD, standard deviation) for each group of interest. Paired data from the oocyte donation pregnancies and their matched controls were analysed using $\mathrm{McNe}$ mar and paired t-tests for categorical and continuous variables, respectively. Multivariable modelling was conducted using conditional logistic regression adjusting for paternal age, age of the oocyte donor, the number of embryos transferred, and singleton/twin pregnancy. Pairs with missing outcome data were not included in our matched analyses. All data were analysed 
using PASW version 17.0 for windows (SPSS Inc., Chicago, IL).

\section{Results}

Characteristics of the oocyte recipients and their matched controls

Overall, the oocyte donation programme resulted in the birth of 375 children out of 294 pregnancies (see Additional file 1: Table S1). Among pregnancies that reached 20 weeks of gestation, $97.9 \%$ resulted in a live birth. The multiple birth rate was 30.3\% (89/294). Singleton pregnancies ended in $2.0 \%$ of cases with a stillbirth, while the stillbirth rate among twin pregnancies was $2.3 \%$. None of the pregnancies was ended by an elective interruption. Additional file 1: Table S1 lists further characteristics of this oocyte recipient cohort of 294 OD pregnancies.

An appropriate match was found for 205 ODpregnancies resulting in 262 live births. Table 1 lists characteristics of this oocyte recipient cohort of 205 OD pregnancies, and their $205 \mathrm{AO}$ individually matched controls. Although no matching was performed for paternal age, body mass index (BMI) and smoking behaviour, these parameters did not differ between pregnancies conceived with donated versus those conceived with autologous oocytes. The mean age of the oocyte donors of 30.7 years was significantly younger (almost 6 years) than the mean age of the oocyte recipient and their matches.

\section{Obstetrical outcome after oocyte donation versus autologous matched controls}

The incidence of first trimester vaginal bleeding and pregnancy-induced hypertension was significantly higher in pregnancies conceived with donated oocytes compared to matched controls with autologous oocytes: $20.6 \%$ vs. $10.3 \%$ ( $P$ value for McNemar test $=0.005)$ and $19.1 \%$ vs. $8.3 \%(P=0.002)$, respectively (Table 2$)$. However, no significant difference was found in singleton pregnancies with regard to these obstetrical complications. No difference was observed in the incidence of nausea or in the incidence of hospital admission for hyperemesis. Although the observed incidences for complications such as pre-eclampsia $(11.8 \%$ vs. $6.4 \%)$, HELLP syndrome $(0.98 \%$ vs. $0.59 \%)$ or gestational diabetes $(7.4 \%$ vs. $3.4 \%)$ were almost twice as high in pregnancies after oocyte donation these differences were not statistically significantly different.

\section{Infant outcome after oocyte donation versus autologous matched controls}

Gestational age, birth weight, height and head circumference and the calculated standard deviations scores were comparable for both groups (Table 3). The children of oocyte recipients were not at increased risk for low-

Table 1 Characteristics of the oocyte recipients and their individually matched controls

\begin{tabular}{|c|c|c|c|c|c|c|c|c|c|c|}
\hline & \multirow[t]{2}{*}{ Available data (\%) } & \multicolumn{3}{|c|}{ All pregnancies $(n=205)$} & \multicolumn{3}{|c|}{ Singletons $(n=148)$} & \multicolumn{3}{|c|}{ Twins $(n=57)$} \\
\hline & & DO & AO & $\mathbf{P}$ & DO & AO & $\mathbf{P}$ & $\mathrm{DO}$ & AO & $P$ \\
\hline \multicolumn{11}{|l|}{ Age } \\
\hline \multirow{2}{*}{$\begin{array}{l}\text { Recipient (DO) or ICSI } \\
\text { patient (AO) (\%; SD) }\end{array}$} & $410 / 410$ & 36.0 & 36.0 & 0.37 & 36.3 & 36.2 & 0.24 & 35.4 & 35.4 & 0.66 \\
\hline & $(100)$ & $(4.5)$ & $(4.5)$ & & $(4.5)$ & $(4.5)$ & & $(4.4)$ & $(4.4)$ & \\
\hline Donor & $406 / 410$ & 30.7 & 36.1 & $<0.001$ & 31.0 & 36.3 & $<0.001$ & 29.8 & 35.4 & $<0.001$ \\
\hline$(\% ; S D)$ & (99) & $(4.4)$ & $(4.4)$ & & $(4.3)$ & $(4.5)$ & & $(4.6)$ & $(4.4)$ & \\
\hline Partner & $400 / 410$ & 38.1 & 39.0 & 0.90 & 38.3 & 39.1 & 0.23 & 37.6 & 38.9 & 0.19 \\
\hline$(\% ; S D)$ & $(97.5)$ & $(6.4)$ & $(6.7)$ & & $(6.2)$ & $(6.7)$ & & $(6.9)$ & $(6.5)$ & \\
\hline Parity & $410 / 410$ & 0.23 & 0.23 & 0.78 & 0.2 & 0.2 & 0.32 & 0.2 & 0.3 & 0.66 \\
\hline$(\% ; S D)$ & $(100)$ & $(0.5)$ & $(0.5)$ & & $(0.5)$ & $(0.5)$ & & $(0.5)$ & $(0.5)$ & \\
\hline Ethnicity & $410 / 410$ & $202 / 205$ & $202 / 205$ & 1 & $146 / 148$ & $146 / 148$ & 1 & $55 / 57$ & $55 / 57$ & 1 \\
\hline (\% Caucasian mothers) & $(100)$ & $(98.5)$ & $(98.5)$ & & $(98.6)$ & $(98.6)$ & & $(96.5)$ & $(96.5)$ & \\
\hline Sex baby & $524 / 524$ & $129 / 262$ & $123 / 262$ & 0.52 & $66 / 148$ & $66 / 148$ & 1 & $63 / 114$ & $57 / 114$ & 0.52 \\
\hline (\% male) & $(100)$ & $(49.2)$ & $(46.9)$ & & $(44.6)$ & $(44.6)$ & & (55.3) & $(50.0)$ & \\
\hline $\mathrm{BMI}$ & $222 / 410$ & 23.3 & 23.2 & 0.92 & 23.7 & 23.1 & 0.35 & 22.1 & 23.5 & 0.14 \\
\hline$(\% ; S D)$ & $(54.1)$ & $(4.4)$ & $(3.2)$ & & $(4.7)$ & (3.4) & & (3.4) & (3.6) & \\
\hline Smoking & $187 / 410$ & $5 / 37$ & $6 / 37$ & 1 & $5 / 31$ & $6 / 31$ & 1 & 0 & 0 & 1 \\
\hline$(\% ; S D)$ & $(45.6)$ & $(13.5)$ & $(16.2)$ & & $(16.1)$ & $(19.3)$ & & & & \\
\hline
\end{tabular}


Table 2 Obstetrical outcome in pregnancies with donated oocytes versus individually matched pregnancies with autologous oocytes

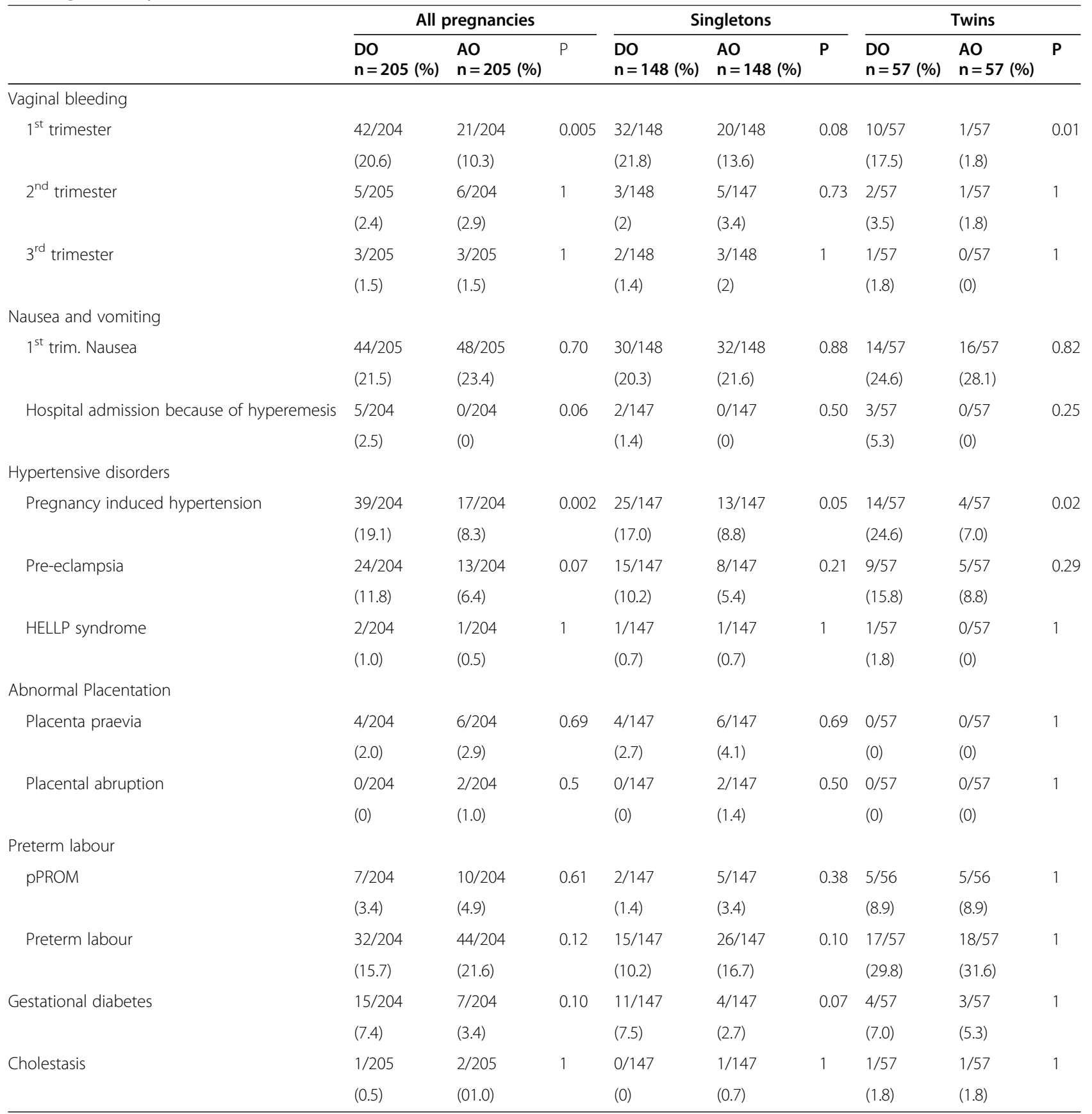

Paired $\mathrm{t}$ tests for continuous variables and McNemar test for categorical variables.

$D O$ Donated oocyte; $A O$ Autologous oocyte.

Categorical variables are presented as numerator and denominator values (\%), and continuous variables as mean (SD, standard deviation) for each group of interest.

birth-weight (LBW), very-low-birth weight (VLBW) or poor Apgar scores. A higher incidence of preterm birth was observed in singletons and twin pregnancies after oocyte donation: $14.2 \%$ vs. $12.2 \%$ ( $P$ value for McNemar test $<0.001)$ and $64.9 \%$ vs. $57.1 \%$ ( $P$ value for McNemar test $<0.001)$, respectively. However, the mean gestational age, as well as the delivery rate before 34 weeks was not different.

\section{Mode of delivery}

Patients who conceived with donor oocytes were more likely to deliver by caesarean section (Table 4; 
Table 3 Infant outcome in pregnancies with donated oocytes versus individually matched pregnancies with autologous oocytes

\begin{tabular}{|c|c|c|c|c|c|c|c|c|c|}
\hline & \multicolumn{3}{|c|}{ All pregnancies } & \multicolumn{3}{|c|}{ Singletons } & \multicolumn{3}{|c|}{ Twins } \\
\hline & DO & AO & $\mathbf{P}$ & $\mathrm{DO}$ & AO & $\mathbf{P}$ & $\mathrm{DO}$ & AO & $\mathbf{P}$ \\
\hline Live births & 262 & 262 & & 148 & 148 & & 114 & 114 & \\
\hline \multicolumn{10}{|l|}{ Gestational age } \\
\hline Mean gestational age & 37.29 & 37.34 & 0.82 & 38.72 & 38.74 & 0.94 & 35.40 & 35.49 & 0.50 \\
\hline$(\mathrm{SD})$ & $(3.1)$ & $(2.9)$ & $(n=259)$ & $(2.3)$ & $(2.0)$ & $(n=147)$ & $(2.9)$ & $(2.8)$ & $(n=112)$ \\
\hline$<37$ weeks of gestation & $95 / 262$ & $82 / 259$ & $<0.001$ & $21 / 148$ & $18 / 147$ & $<0.001$ & $74 / 114$ & $64 / 112$ & $<0.001$ \\
\hline (\%) & $(36.3)$ & $(31.7)$ & & $(14.2)$ & $(12.2)$ & & $(64.9)$ & $(57.1)$ & \\
\hline$<34$ weeks of gestation & $16 / 237$ & $20 / 237$ & 0.60 & $4 / 145$ & $4 / 145$ & 1 & $12 / 92$ & $16 / 92$ & 0.54 \\
\hline (\%) & $(6.8)$ & $(8.4)$ & & $(2.8)$ & $(2.8)$ & & $(13.0)$ & $(17.4)$ & \\
\hline \multicolumn{10}{|l|}{ Birth weight } \\
\hline Mean birth weight & 2832.9 & 2805.3 & 0.56 & 3211.3 & 3183.4 & 0.67 & 2321.2 & 2294.1 & 0.70 \\
\hline (SD) & $(709.9)$ & $(711.1)$ & $(n=254)$ & $(593.5)$ & $(583.4)$ & $(n=146)$ & $(504.7)$ & $(524.9)$ & $(n=108)$ \\
\hline Birth weight & $87 / 256$ & $77 / 260$ & 0.28 & $13 / 147$ & $14 / 147$ & 0.83 & $74 / 109$ & $63 / 113$ & 0.11 \\
\hline$<2500 \mathrm{~g}(\%)$ & (34) & $(29.6)$ & & $(8.8)$ & $(9.5)$ & & $(67.9)$ & $(55.8)$ & \\
\hline Birth weight & $7 / 256$ & $11 / 260$ & 0.48 & $3 / 147$ & $2 / 147$ & 1 & $4 / 109$ & $9 / 109$ & 0.27 \\
\hline$<1500 \mathrm{~g}(\%)$ & $(2.7)$ & $(4.2)$ & & $(2)$ & $(1.4)$ & & $(3.7)$ & (8) & \\
\hline Mean birth length & 48.1 & 48.1 & 1 & 49.7 & 49.6 & 0.81 & 45.7 & 45.8 & 0.795 \\
\hline (SD) & (3.6) & (3.5) & $(n=233)$ & $(2.9)$ & $(2.9)$ & $(n=138)$ & $(3.2)$ & (3.0) & $(n=95)$ \\
\hline Mean head circumference & 33.6 & 33.4 & 0.31 & 34.2 & 34.2 & 0.95 & 32.7 & 32.1 & 0.10 \\
\hline (SD) & $(2.3)$ & $(2.2)$ & $(n=186)$ & $(2.2)$ & $(2.0)$ & $(n=113)$ & $(2.1)$ & $(2.0)$ & $(n=73)$ \\
\hline \multicolumn{10}{|l|}{ APGAR scores } \\
\hline \multicolumn{10}{|l|}{1 minute APGAR scores } \\
\hline \multirow[t]{2}{*}{ Less than 4} & $3 / 224$ & $5 / 233$ & 0.73 & $2 / 132$ & $1 / 133$ & 1.00 & $1 / 92$ & $4 / 100$ & 0.63 \\
\hline & $(1.3)$ & $(2.1)$ & $(n=201)$ & $(1.5)$ & $(0.8)$ & $(n=120)$ & $(1.1)$ & $(4.0)$ & $(n=40)$ \\
\hline \multirow[t]{2}{*}{ Less than 7} & $30 / 224$ & $26 / 233$ & 0.46 & $19 / 132$ & $10 / 133$ & 0.076 & $11 / 92$ & $16 / 100$ & 0.34 \\
\hline & $(13.4)$ & $(11.2)$ & $(n=201)$ & $(14.4)$ & $(7.5)$ & $(n=120)$ & $(12.0)$ & $(16.0)$ & $(n=40)$ \\
\hline \multicolumn{10}{|l|}{5 minute APGAR scores } \\
\hline \multirow[t]{2}{*}{ Less than 4} & $0 / 224$ & $1 / 230$ & 1.00 & $0 / 132$ & 0/131 & NA & $0 / 92$ & $1 / 99$ & 1.00 \\
\hline & $(0)$ & $(0.4)$ & $(n=201)$ & (0) & $(0)$ & & $(0)$ & $(1.0)$ & $(n=41)$ \\
\hline \multirow[t]{2}{*}{ Less than 7} & $4 / 224$ & $4 / 230$ & 1.00 & $3 / 132$ & $1 / 131$ & 0.63 & $1 / 92$ & $3 / 99$ & 1.00 \\
\hline & $(1.8)$ & $(1.7)$ & $(n=201)$ & $(2.3)$ & $(0.8)$ & $(n=118)$ & $(1.1)$ & (3.0) & $(n=41)$ \\
\hline \multicolumn{10}{|l|}{10 minute APGAR scores } \\
\hline \multirow[t]{2}{*}{ Less than 4} & $0 / 217$ & 0/194 & NA & $0 / 131$ & $0 / 118$ & NA & $0 / 86$ & $0 / 76$ & NA \\
\hline & (0) & (0) & & (0) & (0) & & (0) & (0) & \\
\hline \multirow[t]{2}{*}{ Less than 7} & $0 / 217$ & $2 / 194$ & 0.50 & 0/131 & $1 / 118$ & 1.00 & $0 / 86$ & $1 / 75$ & 1.00 \\
\hline & (0) & $(1.0)$ & $(n=163)$ & $(0)$ & $(0.8)$ & $(n=105)$ & (0) & (1.3) & $(n=29)$ \\
\hline
\end{tabular}

Paired $t$ tests for continuous variables and McNemar test for categorical variables.

DO: Donated oocyte; AO: Autologeous oocyte.

Categorical variables are presented as numerator and denominator values (\%), and continuous variables as mean (SD, standard deviation) for each group of interest.

NA, not applicable.

singletons $50.0 \%$ vs. $37.2 \%$ : $P=0.06$; twins $84.2 \%$ vs. $68.4 \% ; P=0.08)$. The significantly higher incidence of caesarean sections appears to be associated with a higher rate of non-elective, rather than elective caesarean sections. Women pregnant with autologous oocytes were more likely to undergo induction of labour and were also more likely to deliver spontaneously (Table 4). 
Table 4 Induction of labour and mode of delivery

\begin{tabular}{|c|c|c|c|c|c|c|c|c|c|}
\hline & \multicolumn{3}{|c|}{ All pregnancies } & \multicolumn{3}{|c|}{ Singletons } & \multicolumn{3}{|c|}{ Twins } \\
\hline & DO (\%) & AO (\%) & $p$ & DO (\%) & $\mathrm{AO}(\%)$ & $\mathbf{P}$ & DO (\%) & $\mathrm{AO}(\%)$ & $P$ \\
\hline Induction of labour (\%) & $16 / 201(8.0)$ & $41 / 201(20.4)$ & $<0.001$ & 16/144 (11.1) & $36 / 144(25.0)$ & 0.004 & $0 / 57(0)$ & $5 / 57(8.7)$ & 0.06 \\
\hline \multicolumn{10}{|l|}{ Mode of delivery } \\
\hline Spontaneous delivery (\%) & $53 / 202(26.2)$ & $84 / 202(41.6)$ & 0.002 & 46/145 (31.7) & $67 / 145(46.2)$ & 0.02 & $7 / 57(12.3)$ & $17 / 57(29.8)$ & 0.04 \\
\hline Assisted vaginal delivery (\%) & $30 / 202(14.9)$ & 25/202 (12.4) & 0.56 & 28/145 (37.8) & 24/145 (26.4) & 0.65 & $2 / 57(3.5)$ & $1 / 57(1.8)$ & 1 \\
\hline Forceps* $(\%)$ & 9/30 (30) & $5 / 25(20)$ & & $9 / 28(32.1)$ & $4 / 24(16.7)$ & & $0 / 2(0)$ & $1 / 1(100)$ & \\
\hline Ventouse* $(\%)$ & $21 / 30(70)$ & $20 / 25(80)$ & & 19/28 (67.9) & 20/24 (83.3) & & $2 / 2(100)$ & $0 / 1(0)$ & \\
\hline Caesarean section (\%) & 119/202 (58.9) & $93 / 202(46.0)$ & 0.01 & $71 / 145(50.0)$ & $54 / 145(37.2)$ & 0.06 & $48 / 57(84.2)$ & $39 / 57(68.4)$ & 0.08 \\
\hline Elective c. Section (\%) & $55 / 119(46.2)$ & 61/93 (65.6) & & $31 / 71$ (43.7) & $33 / 54(61.1)$ & & 24/48 (50.0) & 28/39 (71.8) & \\
\hline
\end{tabular}

Paired t tests for continuous variables and McNemar test for categorical variables.

DO: Donated oocyte; AO: Autologeous oocyte.

Categorical variables are presented as numerator and denominator values (\%), and continuous variables as mean (SD, standard deviation) for each group of interest.

*Forceps and Ventouse deliveries as proportion of all assisted vaginal deliveries.

** Elective caesarean sections as proportion of all caesarean sections.

\section{Multivariate logistic regression analysis}

After testing all the parameters in the multivatiate regression model, after adjusting for paternal age, donor age, the number of embryos transferred, and singleton/twin pregnancy, the only factors that remained statistically significant were first trimester vaginal bleeding and $\mathrm{PIH}$, with matched odds ratios (95\% confidence limits) of 1.49 (1.04-2.15) and 1.50 (1.02-2.21), respectively (Table 5).

\section{Discussion}

Our analysis provides evidence that oocyte donation is associated with an increased risk of $\mathrm{PIH}$ and first

\begin{tabular}{lll}
$\begin{array}{l}\text { Table } 5 \text { Obstetrical outcome in pregnancies with donated } \\
\text { oocytes versus individually matched pregnancies with }\end{array}$ \\
$\begin{array}{l}\text { autologous oocytes further adjusted for paternal age, } \\
\text { oocyte age, number of embryos per transfer, and } \\
\text { singleton/twin pregnancy }\end{array}$ & Matched OR & $\mathbf{9 5 \%} \mathbf{C l}$ \\
\hline Obstetrical outcome parameter & & \\
\hline Vaginal bleeding & 1.47 & $1.02-2.12$ \\
$1^{\text {st }}$ trimester & 1.27 & $0.52-3.12$ \\
$2^{\text {nd }}$ trimester & 0.98 & $0.24-3.99$ \\
$3^{\text {rd }}$ trimester & & \\
Nausea and vomiting & 0.87 & $0.58-1.29$ \\
$1^{\text {st }}$ trimester nausea & 1.88 & $0.59-6.04$ \\
Hospital admission because of hyperemesis & & \\
Hypertensive disorders & 1.50 & $1.02-2.19$ \\
Pregnancy induced hypertension & 1.31 & $0.83-2.08$ \\
Pre-eclampsia & & $0.29-2.13$ \\
Preterm labour & 0.78 & $0.47-1.16$ \\
PPROM & 0.74 & $0.85-2.98$ \\
\hline $\begin{array}{l}\text { Preterm labour } \\
\text { Gestational diabetes }\end{array}$ & 1.59 & \\
\hline
\end{tabular}

trimester vaginal bleeding. Although oocyte donation cycles appear to be associated with relatively high incidences of preeclampsia, gestational diabetes, preterm delivery, caesarean section and incidences of labour induction their incidences were not significantly increased in this study.

To our knowledge this is the largest cohort study examining the effect of oocyte donation on obstetric and perinatal outcomes including literally more patients than all the previous controlled trials cumulatively [12]. Furthermore, this study includes adequate matching for confounding factors, which was facilitated by a large prospectively collected ART outcome database. Another strength of the study is that both cohorts of pregnancies deriving from donor and autologous oocytes were matched, not only for age parity and plurality as previous trials did [12], but also for maternal ethnicity which may be a factor associated with the incidence of preeclampsia [13-15].

Previous studies that compared the obstetrical outcomes after oocyte donation and after standard in-vitro fertilisation (IVF) in patients of the same age group $[16,17]$ have also reported an increased incidence of PIH. Söderström et al. found a significantly higher incidence of hypertensive disorders in the oocyte recipients although these individuals also had a significantly higher incidence of primiparity. Recently, the obstetrical outcome after oocyte donation compared with a selected control group, matched for potential confounding parameters, was the focus of research in three observational studies [18-20]. Nevertheless, in all three studies, the average age of individuals in the control groups was significantly lower than the age of the oocyte recipients. Several trials have shown that the incidence of preeclampsia is increased in oocyte recipients; although we 
did find an increase of $5.4 \%$ in oocyte recipient this was not significant $(\mathrm{p}=0.07)$. This could be attributed to the fact that we matched for all potential confounding factor, including ethnicity. The only study that has similar design is the trial by Klatsly et al. (2010); nonetheless, our trial literally outnumbers this trial by 2.5 times including more than 400 patients in total.

Oocyte donation treatment confers a unique group of pregnancies partly because this method potentially extends biological fertility to ages well beyond the average age of menopause [21,22]. It is therefore important, but difficult, to identify an adequate control population without multiple confounding factors. Since nationwide US epidemiological data suggest that the risk of preeclampsia increases by $30 \%$ for every additional year beyond the age of 34 [23] we decided to match cases and controls according to their age. The primary purpose of the current study was to investigate the effect of donation; therefore, individual case-control matching also aimed to control for the confounding effect of parity, as nulliparity almost triples the risk for pre-eclampsia (2.91, 1.28 to 6.61) [24]. A possible limitation to the present study is the limited registration of the maternal risk factors BMI (54.1\%) and smoking behaviour (45.6\%). However, the available data showed that the incidence was similar in the two groups. Because no match was found for all OD pregnancies in women older than 43 years of age our comparative analysis do not allow to provide any statement regarding obstetrical or birth outcomes for OD pregnancies in this older age group.

Although several authors reported higher incidences of first trimester bleeding in ART pregnancies as compared to spontaneous pregnancies, it still remained unclear whether oocyte donation and the underlying mechanism leading to first trimester bleeding conferred two independent risk factors [25]. One study compared pregnancy outcomes after oocyte donation $(n=51)$ with those after IVF pregnancies and observed a significant increase of first trimester bleeding [17]. However, two further studies $(n=50 ; n=71)$ did not observe a difference between these two populations [18,20]. In the current study $(\mathrm{n}=205)$ we report a significant increase in first trimester bleeding (OR: 1.49; 95CI 1.036-2.150) in comparison with a matched control group.

Ongoing spontaneous pregnancies complicated by first-trimester bleeding confer an increased risk for preterm birth and lower birth weight [26,27]. De Sutter et al. found that the higher incidence of first-trimester bleeding was also associated with an increased risk for pregnancy complications in pregnancies following ART [28]. The study reported a lower mean duration of pregnancy and lower birth weight in pregnancies complicated with first trimester vaginal bleeding. However, in our series, the significant increase in first trimester bleeding did not negatively affect the perinatal outcome. The reported higher incidence of first trimester bleeding in ongoing OD pregnancies may possibly be explained by a reduced miscarriage vulnerability to first trimester bleeding. However, this hypothesis cannot be confirmed by the our data, as the matched controls were selected from pregnancies reaching 20 weeks of gestation aimed at evaluating the neonatal outcome.

First-trimester vaginal bleeding may indicate underlying placental dysfunction as it is associated with increased risks of preeclampsia or placental abruption [27]. Our study did not demonstrate an increased risk for any of these obstetrical complications in pregnancies complicated with first trimester bleeding.

As all donated oocytes in our centre undergo fertilisation by intra cytoplasmic sperm injection (ICSI] we selected control patients from our ICSI population. A meta-analysis of eight studies found that the risk for pre-eclampsia was significantly increased in women undergoing ART, with odds ratio of 1.55 (95\% CI 1.231.95) [29]. Our data show that oocyte donation appears not to further increase that risk. Four meta-analyses concluded that compared with spontaneously conceived singletons, pregnancies after assisted fertilisation are more likely to be complicated by prematurity or low birth weight [29-32]. However, a large population-based cohort study comparing birth weight and gestational age between siblings born to women who had conceived both spontaneously and after ART concluded that the observed increased risks are attributable to the factors leading to infertility, rather than to the reproductive technology itself [33].

Conditional logistic regression was performed adjusted for paternal age, donor age and the number of embryos transferred. The influence of paternal genes on normal development and function of the placenta in human is known [34]. Paternal age is considered as a possible risk factor because of a potential mechanism leading to placental dysfunction associated with first trimester bleeding, PIH and preeclampsia [35]. Moreover, there are data suggesting a link between paternal age and placental abruption [36]. The mean age of the partner did not differ between pregnancies with donated versus autologous oocytes and further statistical analysis did not demonstrate any correlation between paternal age and adverse outcome in our series. Although both OD and control pregnancies were conceived after ICSI fertilisation, the indication for the ICSI technique differs. The inability to assess the impact of severe male infertility in the control population is a limitation to the study as this factor is known to affect pregnancy outcome.

Hypertensive disorders in pregnancy have a higher incidence in women of advanced age [37,38]. As the ages of the oocyte donor and the recipient differ significantly 
in an oocyte donation population, the logistic regression analysis was further adjusted for age of the oocyte donor in order to assess its possible influence. The age of the oocyte did not appear to influence the obstetrical or perinatal outcome.

Meta-analyses have reported that singleton children born after ART have an approximately twofold risk of being born preterm [29-31]. We observe similarly high incidences of pre-term birth in pregnancies after oocyte donation and in ICSI pregnancies (14.2\% versus $12.2 \%)$.

As previously reported, a significantly higher incidence of delivery by caesarean section is observed in OD pregnancies. The higher incidence of caesarean sections appears to be associated with a higher proportion of non-elective, rather than elective caesarean sections. In spite of a significantly lower incidence of induction of labour, OD pregnancies are significantly more likely to end by a non-elective caesarean section. It has been argued that a higher level of concern underlies the observed increased incidence of caesarean birth $[4,5,39]$. However, ICSI pregnancies with autologous oocytes have also been associated with a higher level of concern [40].

\section{Conclusion}

In summary, our study demonstrates that oocyte donation treatment is associated with an increased risk of first trimester bleeding and pregnancy induced hypertension in oocyte recipients. A major strength of our approach is that we largely controlled for known and important confounding factors. Although the obstetrical and perinatal outcomes are satisfactory, caution is mandatory in women with other risk factors undergoing egg donation.

\section{Additional file}

Additional file 1: Table S1. Obstetrical and infant outcome in oocyte recipients.

\section{Competing interests}

The authors declare that they have no competing interests.

\section{Authors' contribution}

DS idea, design and interpretation of data, writing of paper. MB statistical analysis, data collection. PH statistical analysis, interpretation of data. NPP interpretation of data, critical revision. MDV critical revision. GV critical revision. MC critical revision. PD idea, interpretation of data, approval of final version of paper. All authors read and approved the final manuscript.

Received: 6 January 2012 Accepted: 4 May 2012

Published: 6 June 2012

\section{References}

1. Lutjen P, Trounson A, Leeton J: The establishment and maintenance of pregnancy using in vitro fertilization and embryo donation in a patient with primary ovarian failure. Nature 1984, 307:174-175.
2. Rosenwaks Z: Donor eggs: their application in modern reproductive technologies. Fertil Steril 1987, 47:895-909.

3. Serhal PF, Craft I: Oocyte donation in 61 patients. Lancet 1989 ii:1185-1187.

4. Blanchette $\mathrm{H}$ : Obstetric performance of patients after oocyte donation. Am J Obstet Gynecol 1993, 168:1803-1809.

5. Pados G, Camus M, Van Steirteghem A, Bonduelle M, Devroey P: The evolution and outcome of pregnancies from oocyte donation. Hum Reprod 1994, 9:538-542.

6. Abdalla HI, Billett A, Kan AKS: Obstetric outcome in 232 ovum donation pregnancies. Br J Obstet Gynaecol 1998, 105:332-337.

7. Sheffer-Mimouni G, Mashiach S, Dor J, Levran D, Seidman DS: Factors influencing the obstetric and perinatal outcome after oocyte donation. Hum Reprod 2002, 17:2636-2640.

8. Edgar $A B$, Wallace WHB: Pregnancy in women who had cancer in childhood. Eur J of Cancer 2007, 43:1890-1894.

9. Borchers AT, Naguwa SM, Keen CL, Gershwin E: The implications of autoimmunity and pregnancy. J Autoimmunity 2010, 34:287-299.

10. Ueda Y, Enomoto T, Miyatake T, Fujita M, Yamamoto R, Kanagawa T, Shimizu H, Kimura T: Fertil Steril 2010, 94:78-84

11. Bonduelle M, Legein J, Derde M-P, Buysse A, Schietecatte J, Wisanto A Devroey P, Van Steirteghem A, Liebaers I: Comparative follow-up study of 130 children born after intracytoplasmic sperm injection and 130 children born after in-vitro fertilization. Hum Reprod 1995, 10:3327-3331.

12. Klatsky PC, Delaney S, Caughey AB, Tran ND, Schattman GL, Rozenwaks Z: The role of embryonic origin in preeclampsia. Obstetrics and Gynecology 2010, 116(6):1387-92.

13. Caughey AB, Stotland NE, Washington AE, Escobar GJ: Maternal ethnicity, paternal ethnicity, and parental ethnic discordance: predictors of preeclampsia. Obstet Gynecol 2005, 106(1):156-161.

14. Bodmar LM, Catov JM, Roberts JM: Racial/ethnic differences in the montly variation of preeclampsia incidences. Am J Obstet Gynecol 2007 196(324):e1-e5.

15. Shental O, Friger M, Sheiner E: Ethnic differences in the montly variation of preeclampsia among Bedouin and Jewish parturients in the Negav. Hypertension in pregnancy 2010, 29:342-349.

16. Friedman F Jr, Copperman, Broadman ML: Perinatal outcome after embryo transfer in ovum recipients. J Reprod Med 1996, 41:640-644.

17. Sönderström-Anttila V, Tiitinen A, Foudila T, Hovatta O: Obstetric and perinatal outcome after oocyte donation: comparison with in-vitro fertilization pregnancies. Hum Reprod 1998, 13:483-490.

18. Wiggins DA, Main E: Outcomes of pregnancies achieved by donor egg in vitro fertilisation - a comparison with standard in vitro fertilisation pregnancies. Am J Obstet Gynecol 2005, 192:2002-2008.

19. Henne MB, Zhang M, Paroski S, Kelshikar B, Westphal LM: Comparison of obstetric outcomes in recipients of donor oocytes vs; women of advanced maternal age with autologous oocytes. J Reprod Med 2007, 52:585-590.

20. Krieg SA, Henne MB, Westphal LM: Obstetric outcomes in donor oocyte pregnancies compared with advanced maternal age in in vitro fertilization pregnancies. Fertil Steril 2008, 90:65-70.

21. Antinori S, Versaci C, Hossein Gholami G: Oocyte donation in menopausal women. Hum Reprod 1993, 8:1487-1490.

22. Antinori $S$, Versaci $C$, Panci $C$ : Fetal and maternal morbidity and mortality in menopausal women aged 45-63 years. Hum Reprod 1995, 10:464-469.

23. Saftlas AF, Olson DR, Franks Al, Atrash HK, Pokras R: Epidemiology of preeclampsia and eclampsia in the United States, 1979-1986. Am J Obstet Gynecol 1990, 163:460-465.

24. Duckitt K, Harrington D: Risk factors for pre-eclampsia at antenatal booking: systemic review of controlled studies. BMJ 2005 330:1-7.

25. Goldman JA, Ashkenazi J, Ben-David M, Feldberg D, Dicker D, Voliovitz I: First trimester bleeding in clinical IVF pregnancies. Hum Reprod 1988, 3:807-809.

26. Strobino B, Pantel-Silverman J: Gestational vaginal bleeding and pregnancy outcome. Am J Epidemiol 1989, 129:806-815.

27. Weiss JL, Malone FD, Vidaver J, Ball RH, Nyberg DA, Comstock CH, Hankins GD, Berkowitz RL, Gross SJ, Ddugoff L: Threatened miscarriage: risk factor for poor pregnancy outcome, a population based screening study. Am J Obstet Gynaecol 2004, 190:745-750. 
28. De Sutter P, Bontinck J, Schutyser V, Van der Elst J, Gerris J, Dhont M: First-trimester bleeding and pregnancy outcome in singletons after assisted reproduction. Hum Reprod 2006, 21:1907-1911.

29. Jackson RA, Gibson KA, Wu YW, Croughan MS: Perinatal outcomes in singletons following in vitro fertilization: a meta-analysis. Obstet Gynecol 2004, 103:551-563.

30. Helmerholst FM, Perquin DA, Donker D, Keirse MJ: Perinatal outcome of singletons and twins after assisted conception: a systematic review of controlled studies. Br Med J 2004, 328:261-265.

31. McGovern PG, Llorens AJ, Skurnick JH, Weiss G, Goldsmith LT: (2004) Increased risk of preterm birth in singleton pregnancies resulting from in vitro fertilization-embryo transfer or gamete intrafallopian transfer: a meta-analysis. Fertil Steril 2004, 82:1514-1520.

32. McDonald DS, Murphy K, Beyene J, Ohlsson A: Perinatal outcome of singleton pregnancies achieved by in vitro fertilization: a systematic review and meta-analysis. J Obstet Gynaecol Can 2005, 27:449-459.

33. Romundstad LB, Romundstad PR, Sunde A, von Düring V, Skjaerven R, Gunnell D, Vatten $L$ : Effects of technology or maternal factors on perinatal outcome after assisted fertilisation: a population-based cohort study. Lancet 2008, 30:694-695.

34. Wagschal A, Feil R: Genomic imprinting in the placenta. Cytogenet Genome Res 2006, 113:90-98.

35. Harlap S, Paltiel O, Deutsch L, Knaanie A, Masalha S, Tiram E, Caplan LS, Malaspina D, Friedlander Y: Paternal age and preeclampsia. Epidemiology 2002, 13:660-667.

36. Tan H, Wen SW, Walker M, Demissie K: Missing paternal demographics: a novel indicator for identifying high risk population of adverse pregnancy outcomes. BMC Pregnancy Childbirth 2004, 4(1):21.

37. Paulson RJ, Boostanfar R, Saadat P, Mor E, Tourgeman DE, Slater CC: Pregnancy in the sixth decade of life: obstetric outcomes in women of advanced reproductive age. JAMA 2002, 288:2320-2323.

38. Jacobsson B, Ladfors L, Milsom I: Advanced maternal age and adverse perinatal outcome. Obstet Gynecol 2004, 104:727-733.

39. Sauer MV, Paulson RJ, Lobo RA: Oocyte donation to women of advanced reproductive age: pregnancy results and obstetrical outcomes in patients 45 years and older. Hum Reprod 1996, 11:2540-2543.

40. Tanbo T, Dale P, Lunde O: Obstetric outcome in singleton pregnancies after assisted reproduction. Obstet Gynecol 1995, 86:188-192.

doi:10.1186/1477-7827-10-42

Cite this article as: Stoop et al:: Obstetric outcome in donor oocyte pregnancies: a matched-pair analysis. Reproductive Biology and Endocrinology 2012 10:42.

\section{Submit your next manuscript to BioMed Central and take full advantage of:}

- Convenient online submission

- Thorough peer review

- No space constraints or color figure charges

- Immediate publication on acceptance

- Inclusion in PubMed, CAS, Scopus and Google Scholar

- Research which is freely available for redistribution 